\title{
Cognitive therapy and Winnie-the-Pooh
}

\author{
GARY HosTy, Registrar, All Saints Hospital, Birmingham BS18 5SD
}

"Here is Edward Bear, coming downstairs now, bump, bump, bump, on the back of his head, behind Christopher Robin. It is as far as he knows, the only way of coming downstairs, but sometimes he feels that there really is another way, if only he could stop bumping for a moment and think of it."

Winnie-the-Pooh A. A. Milne (1926)

A. A. Milne's classic of children's literature was first published in 1926; one year before Pavlov described classical conditioning, four years before Watson launched behaviourism and perhaps 50 years before the beginnings of cognitive therapy. In the first paragraph quoted above the author anticipates these developments, demonstrating an instinctive grasp of the central role of cognition in the generation maintenance and resolution of human problems. As the cycle of stories, describing the incidents and interactions among a group of animals, progresses, several important principles of cognitive therapy are presented.

One of the clearest examples of this can be seen in the story entitled 'Piglet meets a Heffalump'. In this episode, Winnie-the-Pooh and Piglet become convinced of the belief of a new animal in the Hundred Acre Wood, the Heffalump, and set about catching it. At the climax of this story, Pooh has become trapped in the hole he has dug to catch the Heffalump. He has also accidentally stuck his head in a honey pot and is unable to remove it, the honey pot having been intended as bait to attract the Heffalump to the hole. He is then stumbling around in the hole with his head encased in the honey pot. It is difficult to construct a more apt or striking metaphor for the individual 'stuck' in an habitual maladaptive belief system. While Pooh is in this state Piglet cautiously approaches. He has heard noises from the hole which he has attributed to the trapped Heffalump. Piglet looks into the hole and perceives Pooh as a frightening monster due to the influence on his perception of his cognitive set. Piglet runs in extreme anxiety to Christopher Robin. Christopher Robin returns to the hole with Piglet and offers, through laughter, and alternative interpretation of the situation. At this moment Pooh falls and the honeypot is broken.
It is then that both Pooh and Piglet experience a dramatic modification in their thinking, resulting in a cessation of Piglet's anxiety and enabling Pooh to begin relating to the world in a more adaptive manner.

There are numerous similarly vivid demonstrations of cognitive theory and practice throughout the group of fable-like stories concerning Pooh. There is insufficient space in an article of this nature to provide a comprehensive coverage of these. I do, however, think it is appropriate to mention briefly three of the more important examples.

Firstly, the character of Eeyore must be ranked among the most clear and consistent descriptions of an individual prone to continual self-defeating assumptions, with resultant depressive symptomology, occurring in any literary work. Many of the 'Hums of Pooh' stand as examples of effective constructive 'self talk' which Pooh employs to control negative cognitions and enables him to deal with a variety of stressful circumstances in an adaptive and constructive manner.

Finally, the episode in which Pooh escapes a flood using an upturned umbrella as a boat (tellingly named 'The brain of Pooh') can be seen as a memorable symbol of the value of challenging and even 'turning up-side-down' an individual's habitual cognitive strategies. It would, of course, be simplistic to suggest the viewpoint discussed here as the only interpretation that can be made of this text. A traditional psycho-analytical perspective on Winniethe-Pooh has been previously published (Crewes, 1979) and an explanation of the principles of Taoism through the characters of Winnie-the-Pooh is also available (Hoff, 1982).

My suggestion that Winnie-the-Pooh can be constructively studied from the point of view of cognitive theory is intended as a complementary and not competing perspective; it must also be admitted that with a text of this nature, there is a great deal of scope for other perspectives.

\section{References}

Crewes, F. C. (1979) The Pooh Perplex. Robin Clarke. Hoff, B. (1982) Tao of Pooh. London: Methuen. 